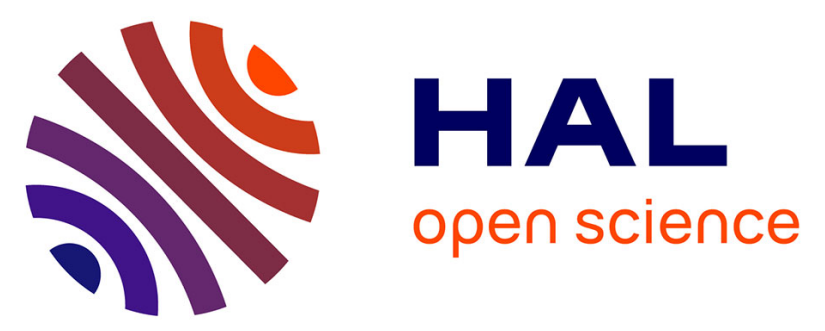

\title{
A unique ferrous iron binding mode is associated to large conformational changes for the transport protein FpvC of Pseudomonas aeruginosa
}

Armelle Vigouroux, Magali Aumont-Nicaise, Alain Boussac, Loïc Marty, Léa Lo Bello, Pierre Legrand, Karl Brillet, Isabelle J. Schalk, Solange Moréra

\section{To cite this version:}

Armelle Vigouroux, Magali Aumont-Nicaise, Alain Boussac, Loïc Marty, Léa Lo Bello, et al.. A unique ferrous iron binding mode is associated to large conformational changes for the transport protein FpvC of Pseudomonas aeruginosa. FEBS Journal, 2019, 287 (2), pp.295-309. 10.1111/febs.15004 . hal02294880

\section{HAL Id: hal-02294880 \\ https://hal.science/hal-02294880}

Submitted on 27 Oct 2020

HAL is a multi-disciplinary open access archive for the deposit and dissemination of scientific research documents, whether they are published or not. The documents may come from teaching and research institutions in France or abroad, or from public or private research centers.
L'archive ouverte pluridisciplinaire HAL, est destinée au dépôt et à la diffusion de documents scientifiques de niveau recherche, publiés ou non, émanant des établissements d'enseignement et de recherche français ou étrangers, des laboratoires publics ou privés. 
Received Date : 16-Apr-2019

Revised Date : 18-Jun-2019

Accepted Date : 16-Jul-2019

A unique ferrous iron binding mode is associated to large conformational changes for the transport protein FpvC of Pseudomonas aeruginosa

Running title: Iron bound to the SBP FpvC

Article type : Original Article

Armelle Vigouroux ${ }^{1}$, Magali Aumont-Nicaise ${ }^{1}$, Alain Boussac ${ }^{1}$, Loïc Marty ${ }^{1}$, Léa Lo Bello ${ }^{1}$, Pierre Legrand $^{2}$, Karl Brillet, ${ }^{3, \#}$, Isabelle J. Schalk ${ }^{3} \&$ Solange Moréra ${ }^{1^{*}}$

${ }^{1}$ Institute for Integrative Biology of the Cell (I2BC), CNRS CEA Univ. Paris-Sud, Université ParisSaclay, Avenue de la Terrasse, 91198 Gif-sur-Yvette, France

${ }^{2}$ Synchrotron SOLEIL, L’Orme des Merisiers, Saint Aubin BP48, Gif-sur-Yvette 91198, France

${ }^{3}$ UMR7242, CNRS, Université de Strasbourg, ESBS, Bd Sébastien Brant, F-67412 Illkirch, Strasbourg, France

\# Present address: Université de Strasbourg, CNRS, Architecture et Réactivité de l'ARN, UPR9002, F67000 Strasbourg, France

*Corresponding author: solange.morera@i2bc.paris-saclay.fr; Tel +33169824213

ORCID ID: 0000-0001-7781-0448

Keywords: iron, solute-binding protein, siderophore, pyoverdine, Pseudomonas aeruginosa

This article has been accepted for publication and undergone full peer review but has not been through the copyediting, typesetting, pagination and proofreading process, which may lead to differences between this version and the Version of Record. Please cite this article as doi: $10.1111 /$ febs. 15004

This article is protected by copyright. All rights reserved. 
Abbreviations: PVD, pyoverdine; EPR, electron paramagnetic resonance; SBP, solute-binding protein; RMSD, root mean square deviation; PDB, protein data bank; EDTA, ethylenediaminetetraacetic acid; TCEP, Tris(2-carboxyethyl)phosphine; ITC, isothermal titration microcalorimetry; CD, circular dichroism; DSC, Differential scanning calorimetry.

\footnotetext{
Abstract

Pseudomonas aeruginosa secretes pyoverdine, a major siderophore to get access to iron, an essential nutrient. Pyoverdine scavenges ferric iron in the bacterial environment with the resulting complex internalized by bacteria. Iron release from pyoverdine in the periplasm involves an iron reduction by an inner membrane reductase and two solute-binding proteins (SBPs) FpvC and FpvF in association with their ABC transporter. FpvC and FpvF belong to two different subgroups of SBPs within the structural cluster A: FpvC and FpvF were proposed to be a metal-binding protein and a ferrisiderophore binding protein, respectively. Here, we report the redox state and the binding mode of iron to FpvC. We first solved the crystal structure of $\mathrm{FpvC}$ bound to a fortuitous $\mathrm{Ni}^{2+}$ by single anomalous dispersion method. Using a different protein purification strategy, we determined the structure of $\mathrm{FpvC}$ with manganese and iron, which binds to $\mathrm{FpvC}$ in a ferrous state as demonstrated by electron paramagnetic resonance. FpvC is the first example of a hexahistidine metal site among SBPs in which the $\mathrm{Fe}^{2+}$ redox state is stabilized under aerobic conditions. Using biophysics methods, we showed that FpvC reversibly bind a broad range of divalent ions. The structure of a mutant mimicking the apo FpvC reveals a protein in an open state with large conformational changes when compared with the metal-bound FpvC. These results highlight that the canonical metal site in FpvC is distinct from those yet described in SBPs and they provide new insights into the mechanism of PVD-Fe dissociation in $P$. aeruginosa.
}

This article is protected by copyright. All rights reserved. 


\section{Introduction}

Under physiological conditions, iron mainly exists in one of two readily interconvertible redox states: the reduced $\mathrm{Fe}^{2+}$ ferrous form and the oxidized $\mathrm{Fe}^{3+}$ ferric form. Nonetheless, $\mathrm{Fe}^{2+}$ is rapidly oxidized into $\mathrm{Fe}^{3+}$ in the presence of oxygen and precipitates as a polymeric oxyhydroxide. In order to overcome the problem of iron solubility and availability, Gram-negative bacteria produce and secrete siderophores which are high-affinity extracellular chelators of ferric iron. Thus, they scavenge iron in the bacterial environment prior its transport into bacteria and its use as an essential nutrient[1,2]. The recognition and import of siderophore- $\mathrm{Fe}^{3+}$ complexes across bacterial outer membrane in Gramnegative bacteria involves specific outer membrane transporters[3]. Once in the periplasm, some siderophores will release their iron ion in this cell compartment whereas others will cross the inner membrane and deliver it in the cytoplasm[4]. Mechanisms of iron release from siderophores usually involve an iron reduction step associated sometimes with hydrolysis or chemical modification of the siderophores[4].

The World Health Organization recently defined a global priority pathogen list of antibiotic-resistant bacteria for prioritization of research and development of new antibiotics (http://www.who.int/medicines/publications/WHO-PPL-Short_Summary_25Feb-ET_NM_WHO.pdf). Pseudomonas aeruginosa, which is an opportunistic human pathogen, belongs to the first list as a critical pathogen, produces and secretes a major siderophore pyoverdine (PVD) to acquire iron[5]. PVD, which is composed of a dihydroxyquinoline-type chromophore linked to an octapeptide chain[5], scavenges iron in the bacterial environment, and the formed complex is reabsorbed across the outer membrane by the transporters FpvA and FpvB[6-8]. Iron release from this siderophore into the periplasm involves an iron reduction by the inner membrane reductase FpvG and a recycling of the apo PVD into the extracellular medium by the efflux system PvdRT-OpmQ[9-12]. Iron acquisition by PVD involves as well a SBP-mediated transport system composed of two SBPs, namely FpvF and FpvC[12, 13]. FpvC and FpvF have been shown to bind together and form a FpvFFpvC-siderophore-iron complex in the periplasm[13]. The PVD-Fe ${ }^{3+}$ complex is probably first 
scavenged by the FpvF-FpvC complex before iron reduction and dissociation from PVD[12, 13]. FpvC, is proposed as the $\mathrm{Fe}^{2+}$ chelator in the mechanism of iron release from PVD which brings the ferrous iron to the $\mathrm{ABC}$ transporter FpvDE for its translocation into the cytoplasm [12]. Previous primary sequence alignment[13] indicated that FpvC (317 amino-acid) belongs to a subgroup of the TroA-like SBPs superfamily[14]. According to Berntsson and coworkers[15] who established a cluster system of SBPs classification based on both structural and functional properties, these TroAlike SBPs belongs to the cluster A-1. These SBPs are described as binding different metal ions including $\mathrm{Mn}^{2+}, \mathrm{Fe}^{2+} / \mathrm{Fe}^{3+}, \mathrm{Cu}^{2+}$ and/or $\mathrm{Zn}^{2+}$ and sharing a similar fold composed of two-domain organization connected by a single long $\alpha$-helix. The canonical binding metal ion site is located at the interface of the two domains and is formed by amino-acids from each domain.

In this study, we investigated the structural and biochemical properties of the SBP FpvC from $P$. aeruginosa PAO1 to identify the bound iron redox state and its binding mode. We first structurally characterized the metal binding site of $\mathrm{FpvC}$ via a fortuitous bound $\mathrm{Ni}^{2+}$ from two crystal forms at $1.65 \AA$ and $1.92 \AA$ resolution. Indeed, purification of the His-tag FpvC using nickel-affinity chromatography led to a nickel complex. The structure of a bound iron to His-tag FpvC binding site was obtained from a protein expressed under minimal-media with iron supplementation and purified with an ion-exchange chromatography. Electron paramagnetic resonance (EPR) allowed the determination of the redox state of the bound iron after treatment of FpvC-iron complex with ferricyanide. The coordination of the ferrous ion in FpvC with an octahedral geometry involving six histidines is so far unique among SBPs and iron binding proteins, which display a hexahistidine motif via oligomerization. The structure of apo FpvC at $2.1 \AA$ resolution was obtained from the mutant FpvC-H6G where the six chelated histidines were replaced by glycines. This work provides new insights into the mechanism of PVD-Fe dissociation in P. aeruginosa and the large conformational changes that $\mathrm{FpvC}$ might undertake under this process. Moreover, it also widens our knowledge on the cluster A-1 SBPs about the canonical metal binding site and protein flexibility.

This article is protected by copyright. All rights reserved. 


\section{Results}

FpvC, a SBP from cluster A-1. The mature FpvC expression plasmid is a synthetic gene lacking the first 37 signal sequence residues that serve for the localization to the bacterial periplasm. Nonetheless, the expressed protein contains a C-terminal sequence of 13 residues composed of a TEV cleavage site and a His-tag. The numbering used for the description of residues corresponds to the mature protein of 317 amino acids. Since FpvC shares low sequence identity (less than 26\%) with SBPs of known threedimensional structure, we determined the structure of His-tag FpvC by single anomalous dispersion (SAD) at the absorption $K$-edge of nickel and refined the model up to $1.65 \AA$ resolution (Table 1 , Figure 1a). The monomeric FpvC fold consists of a N-terminal domain (residues 41-170) and a Cterminal domain (residues 199-316) with a long helix (residues 171-198) connecting the two domains. The identity of the fortuitous $\mathrm{Ni}^{2+}$ ion in the crystal was determined from an $\mathrm{X}$-ray fluorescence spectrum measured at SOLEIL synchrotron beamline PROXIMA 2. The $\mathrm{Ni}^{2+}$ ion likely came from the nickel-affinity chromatography used to purify FpvC. The FpvC-Ni ${ }^{2+}$ complex also crystallized in $P 2_{1}$ space group with two identical molecules (root mean square deviation (RMSD) of $0.24 \AA$ for all C $\alpha$ atoms) in the asymmetric unit using the same crystallisation conditions (Table 1) and its structure was determined by molecular replacement at $1.99 \AA$ A resolution using the model determined in the $P 2_{1} 2_{1} 2_{1}$ space group. The three FpvC-Ni ${ }^{2+}$ molecules from both crystal forms are very similar as indicates the average RMSD of $0.4 \AA$ for all $\mathrm{C} \alpha$ atoms.

Modifying the purification protocol of His-tag FpvC expressed under minimal-media and iron supplementation allowed us to obtain the structure of an iron-FpvC complex and a manganese-FpvC complex (Table 1, Figures 1b-c). X-ray fluorescence measured at the synchrotron beamline detected only one type of metal per crystal and identified the presence of iron or manganese in the crystal. The structures of FpvC-iron and FpvC-manganese were determined at $2.75 \AA$ and $2.49 \AA$ resolution, respectively, by molecular replacement using the coordinates of the $\mathrm{FpvC}-\mathrm{Ni}^{2+}$ complex obtained at high resolution. The asymmetric unit of FpvC-iron and FpvC-manganese structures contain two and four identical molecules, respectively (RMSD of $0.23 \AA$ and average RMSD of $0.28 \AA$ for all Ca atoms, respectively).

This article is protected by copyright. All rights reserved. 
All metal-FpvC structures are very similar (average RMSD of $0.35 \AA$ for all $\mathrm{C} \alpha$ atoms) with the loop region 132-141 highly flexible and thus not defined in electron density maps, except for one molecule in the $\mathrm{FpvC}-\mathrm{Mn}^{2+}$ structure (molecule A) where the loop main-chain could be almost built in the electron density maps.

Metal binding site of FpvC. Electron density maps could not discriminate the redox status of the bound iron $\left(\mathrm{Fe}^{2+}\right.$ or $\left.\mathrm{Fe}^{3+}\right)$. Because X-ray photoreduction occurs during data collection[16], the ferrous ion is the form present in the structure, bringing no information on the Fe redox state before X-ray exposure. Therefore, an EPR control was realized to determine the redox state of the iron bound to FpvC in solution. EPR measurements were performed at $4.2 \mathrm{~K}$ at both $\mathrm{pH} 6.5$ and 8 , corresponding to the protein crystallisation and protein purification buffers, respectively. Spectrum a in Figure 2 shows the EPR spectrum recorded on the purified His-Tag FpvC-iron complex $(60 \mu \mathrm{M})$ at $\mathrm{pH}$ 8. The spectrum was identical for His-Tag FpvC-iron complex at pH 6.5 (data not shown). Signals were detected at $g=9.5$ (710 gauss) and $g=4.28$ (1585 gauss). The amplitude of these two signals increased upon the addition of $30 \mu \mathrm{M}$ potassium ferricyanide (spectrum b) and further increased upon the addition of $60 \mu \mathrm{M}$ potassium ferricyanide (spectrum c). The broad signal at 2500 gauss originated from the ferricyanide in excess, which was not reduced in the presence of the protein. These data showed that FpvC binds the ferrous iron form and that this iron is oxidable by ferricyanide. The detection of a ferricyanide signal at concentrations half and similar to that of the protein indicates that the redox potential of the iron is close to $400( \pm 60) \mathrm{mV} v s$ NHE. From the shape of the EPR spectrum, the zero field splitting parameter $\mathrm{E} / \mathrm{D}$ of $\mathrm{Fe}^{3+}$ was in an almost completely rhombic environment [17]. The same experiment was performed on the crystals of FpvC-iron complex before X-ray exposure leading to the same result (data not shown).

The bound $\mathrm{Ni}^{2+}, \mathrm{Fe}^{2+}$ and $\mathrm{Mn}^{2+}$ ions are located at the same positions in the cleft between the two domains of FpvC. Their near-perfect octahedral geometry involves six histidines (His77, His102 and His147 from the N-terminal domain and His213, His235 and His286 from the C-terminal domain)

This article is protected by copyright. All rights reserved. 
(Figures 1d-f), out of the seven of FpvC, being at distance (NE2 atom) range from $2.11 \AA$ to $2.27 \AA$ with the nickel ion, from $2.13 \AA$ to $2.44 \AA$ with the iron ion and from $2.14 \AA$ to $2.49 \AA$ with the manganese ion (Table 2). All of the six histidines belong to loop regions connecting secondary structural elements. His77, H286, His147 and His235 define the equatorial plan of the octahedron while His102 and His213 are the opposite vertices on each side of the equatorial plan. His102, His147 and His 286 are deeply buried at the back of the metal cleft while His77 and His235 are closer to the opening of the cleft and seem to close the metal binding site.

Comparison with orthologues. FpvC possesses a typical fold of cluster A-1 within the SBP structural classification[15] as SSM-EBI (http://www.ebi.ac.uk/msd-srv/ssm) reports: RMSD between FpvC and similar SBP structures binding metal range from 2.2 to $2.7 \AA$ over 240 to $251 \mathrm{C} \alpha$ atoms. The best match concerns the structure of YfeA from Yersinia pestis (PDB 5UYE[18] with a RMSD of $2.2 \AA$ over 251 residues and $25 \%$ sequence identity) meaning that there are significant differences between FpvC and the other structures of cluster A-1 SBPs (Figure 1g).

FpvC presents a distinct metal-binding site compared to all other metal-binding SBPs described so far. Previous structures of cluster A-1 SBPs showed four metal-coordinating amino-acids, either 2 His and 2 carboxylates (Glu/Asp) or 3 His and 1 carboxylate (Asp) leading to a tetrahedral or a highly distorted octahedral geometry[18, 19]. FpvC is the first example with a hexahistidine metal site among SBPs. The comparison of its metal binding site with its closest homologue YfeA from Yersinia pestis (His76, His141, Glu207 and Asp 282; PDB 5UYE[18]) shows that only one conserved histidine superimposed (His147 in FpvC and His141 in YfeA) (Figure 1h). The other conserved histidine (His77 in FpvC) is separated from 3.2 A from His76 in YfeA. His213 in FpvC corresponds to Glu207 in YfeA. The three remaining histidines in FpvC (His102, His235, His286) have no structural equivalent amino-acid within cluster A-1 SBPs and the conserved aspartate (Asp282 in YfeA) of cluster A-1 SBPs has no structural equivalence in FpvC (Figure 1h).

This article is protected by copyright. All rights reserved. 
FpvC displays large conformational changes. All attempts to crystallize $\mathrm{FpvC}$ in its apo form were unsuccessful. Thus, we circumvented the issue by using FpvC-H6G, a mutant in which the six metalliganded histidines were replaced by glycine residues to mimic the metal-free SBP. Indeed, FpvCH6G is no longer able to bind a metal ion[12]. All of the six histidines belong to loop regions connecting secondary structural elements, therefore mutating them will likely not affect the secondary structure of the protein. To check this, we determined and compared the secondary structure of apo FpvC and FpvC-H6G mutant by circular dichroïsm. Both proteins share the same secondary structure content in line with what is observed in the crystal structure of FpvC-H6G (Figures 3 and 4 and Table 3). The $2.1 \AA$ structure of FpvC-H6G contains two very similar molecules in the asymmetric unit as indicates the average RMSD of $0.66 \AA$ for all $\mathrm{C} \alpha$ atoms. The structure reveals an open conformation with the site including the 6 Gly residues exposed to the solvent. In contrast to the metal-liganded structures, the full protein is defined in the electron density maps and the flexible loop (residues 132141) is now very well defined and includes an extra helix (residues 135-139) (Figure 4a).

Superposition of the overall structures of the metal-free FpvC-H6G (apo) and metal-bound FpvC (holo) leads to a RMSD of $1.7 \AA$ and shows large conformational changes (Figure 4b). An important change results from a rearrangement in the C-terminal end (residues 198-201) of the interdomain helix, which in the open state forms an extra-helical turn as shown in red color in Figure 4a. Superposition of the N-terminal domains only including a part of the interdomain helix (residues 41190) shows that they are nearly unchanged, RMSD being $0.63 \AA$ for all $\mathrm{C} \alpha$ atoms. Indeed, metal binding has only a local effect with a rearrangement of the loop 73-83 up to $2.6 \AA$ around the ion chelator His77 (Figure 4b). In contrast, metal binding has a drastic effect on the C-terminal domain (residues 191-316) as indicated by the RMSD value of $2.25 \AA$ (Figure $4 \mathrm{~b}$ ). His 213 can move to $5 \AA$ to interact with the metal ion and a large rearrangement up to $12.7 \AA$ of the long loop region (residues 224-240) allows the metal-coordinating His 235 to close the metal binding site (Figure 4b). This latter loop adopts a different conformation and position between the closed and open states. The three remaining metal ligands, His102 and His147 of the N-terminal domain and His286 from the C- 
terminal domain are unchanged (Figure $4 b$ ), because they are deeply buried at the back of the metal cleft. This is not the case for His77, His213 and His235, which are close to the opening of the cleft and thus exposed to solvent in the free-metal form. As it may be expected, these three histidines can move to form the metal binding site upon metal binding.

FpvC can bind a broad range of divalent metals. Using thermal denaturation experiments by differential scanning calorimetry (DSC), a $\mathrm{Tm}$ of $58.96 \pm 0.002^{\circ} \mathrm{C}$ was measured with the purified mature FpvC $(30 \mu \mathrm{M})$ devoid of any tag and endogenous metal (Figure 5a, Table 4). Indeed, this Tm was very similar to that $\left(58.97 \pm 0.002^{\circ} \mathrm{C}\right)$ of $\mathrm{FpvC}$ treated with $1 \mathrm{mM}$ EDTA, a strong chelating agent (Figure 5a, Table 4). FpvC and the reductant agent TCEP led to the same Tm showing that TCEP had no effect on the protein (Figure 5a, Table 4). Although glycine can access a greater range of backbone conformations and allows more flexibility on main chain protein, the FpvC-H6G mutant is more stable than the wild-type apo $\mathrm{FpvC}$ with a $\mathrm{Tm}$ of $62.23 \pm 0.002^{\circ} \mathrm{C}$ (Figure 5a, Table 4).

DCS analyses revealed that $\mathrm{Fe}^{3+}$ did not alter the $\mathrm{Tm}$ of apo $\mathrm{FpvC}$ whereas a significant shift by $\sim 5^{\circ} \mathrm{C}$ was observed with $\mathrm{Fe}^{2+}$ and was more pronounced $\sim 7^{\circ} \mathrm{C}$ with $\mathrm{Fe}^{2+}$ and TCEP (Figure 5b, Table 4). The presence of $\mathrm{Fe}^{3+}$ and TCEP induced two peaks, one corresponding to the Tm of the apo FpvC and the second to that of $\mathrm{FpvC}$ in the presence of $\mathrm{Fe}^{2+}$ meaning that TCEP, as expected, can reduce $\mathrm{Fe}^{3+}$ into $\mathrm{Fe}^{2+}$ (Figure 5b, Table 4) and that $\mathrm{FpvC}$ binds only $\mathrm{Fe}^{2+}$ and not $\mathrm{Fe}^{3+}$. Larger very similar shifts (> $\left.25^{\circ} \mathrm{C}\right)$ were observed for $\mathrm{Zn}^{2+}, \mathrm{Mn}^{2+}, \mathrm{Ni}^{2+}$ and an intermediate shift $\left(<15^{\circ} \mathrm{C}\right)$ was present with $\mathrm{Mg}^{2+}$ and $\mathrm{Ca}^{2+}$. Adding $\mathrm{Co}^{2+}, \mathrm{Cu}^{2+}$ and $\mathrm{Ca}^{2+}$ to $\mathrm{FpvC}$ showed two similar peaks, one corresponding roughly to the intermediate shift and the other one to the larger shift (Figure 5c, Table 4). Addition of EDTA to any FpvC-metal ions complex resulted in an apo FpvC behaviour. Therefore, EDTA can remove each metal including those responsible for the highest $T \mathrm{~m}$ able to strongly stabilize FpvC.

This article is protected by copyright. All rights reserved. 
Binding of $\mathrm{Ni}^{2+}, \mathrm{Zn}^{2+}$ and $\mathrm{Fe}^{2+}$ with TCEP to $\mathrm{FpvC}$ was explored using ITC (Figure 6). Similar dissociation constant $K_{D}$ values of $0.19 \pm 0.02 \mu \mathrm{M}, 0.29 \pm 0.07 \mu \mathrm{M}$ and $0.39 \pm 0.11 \mu \mathrm{M}$ were measured with $\mathrm{Ni}^{2+}, \mathrm{Zn}^{2+}$ and $\mathrm{Mn}^{2+}$, respectively, in agreement with the DSC results where a similar $T \mathrm{~m}$ values were observed. As expected from the DSC data, the affinity of $\mathrm{FpvC}$ for $\mathrm{Fe}^{2+}\left(K_{D}\right.$ of $6.3 \pm$ $2 \mu \mathrm{M}$ ) is lower than those for $\mathrm{Ni}^{2+}, \mathrm{Zn}^{2+}$ and $\mathrm{Mn}^{2+}$ (Figure 6). The microcalorimetry data confirmed the 1:1 binding stoichiometry and revealed a negative enthalpy change. No interaction could be measured between FpvC and PVD or PVD-Fe ${ }^{3+}$ compounds, confirming that $\mathrm{FpvC}$ is unable to bind this siderophore[13].

\section{Discussion}

\section{A hexahistidine metal ion binding site for the SBP FpvC}

This work reveals the structural basis of the SBP FpvC, showing that FpvC belongs to the cluster A-1 of SBPs and displays a canonical metal binding site referred as site 1 for all orthologues. In contrast to the closest structural orthologue Yfea from Y. pestis[18] and its related ZnuA from E.coli[20] or MtsA from S. pyogenes[21], FpvC does not possess other metal binding sites. The presence of the fortuitous nickel in FpvC was unexpected and FpvC likely grabbed the nickel ion during the first step of protein purification. The presence of the iron ion in FpvC was not obvious because the purified protein and the crystals did not show any colour or any unusual spectroscopic properties in the UV-Vis spectrum: iron ions often absorb in visible light wavelength ranges, giving rise to a red colour for hemes and a brownish colour for Fe-S clusters. However, X-ray fluorescence emission scan on each metal crystal showed the presence of either a nickel or an iron. The presence of $\mathrm{Fe}^{2+}$ bound to $\mathrm{FpvC}$ in solution and in the crystals prior to X-ray exposure was confirmed by EPR experiments. EPR detects ferric iron in complex with proteins and not ferrous iron. In the case of purified FpvC-Fe, no iron was observed by EPR, but only after iron oxidation by potassium ferricyanide, proving that the purified FpvC-Fe complex contains the metal under its ferrous form. According to the EPR spectrum of FpvC-Fe (spectrum a in Figure 2), the purified FpvC molecules were loaded with ferrous iron although the 
overall purification process was done under aerobic conditions. This indicates that the hexahistidine site of FpvC has a remarkable ability to stabilize $\mathrm{Fe}^{2+}$ and protect it from natural oxidation.

Another remarkable outcome was that FpvC possesses a canonical metal site, which is atypical in residue composition and distinguishes FpvC from all other cluster A-1 SBPs. Indeed, FpvC displays a hexahistidine coordination site instead of the classical tetracoordinate site through either 2 histidines and 2 carboxylates (Glu/Asp) or 3 His and 1 Asp. These latter four amino-acids have been mentioned as evolutionarily conserved across SBPs from cluster A-1[18]. In contrast, similar hexahistidine coordination of metal has been observed so far in few proteins: the human metal-sequestering hostdefence protein calprotectin (PDBs 4GGF[22] and 5W1F[23]), the $\beta \gamma$-crystallin from $M$. thermophile (PDB 5HT7)[24], the membrane-piercing proteins gpV (PDB 3QR7)[25] and gp138 (PDB 3PQH)[25] of bacteriophages P2 and $\phi 92$, respectively, and the receptor-binding domain of phage T4 (PDB 2XGF)[26] and phage $\phi 11$ (PDB 5EFV)[27], all able to chelate iron. It is noteworthy that, unlike the monomeric FpvC, all these proteins are oligomeric and their binding metal site is formed at the oligomeric interface. Indeed, the dimeric human calprotectin brings 2 histidines from a monomer and 4 from the other to create the metal site. The remaining proteins are trimeric and each monomer contains a pair of histidines. Three pairs of these histidines create a nearly perfect octahedral coordination shell for the iron ion positioned along the 3-fold axis of the trimer. It is also noteworthy that these phage proteins and FpvC are all colourless in solution[25-27] meaning that the metalbinding hexahistidine site does not allow any iron colour observation. In agreement, crystals of $\left[\mathrm{Fe}(\text { imidazole })_{6}\right]^{2+}$ are colourless [28].

\section{Large conformational changes upon ligand binding}

Here, we also showed that FpvC is a flexible protein. Several attempts to obtain the structure of apo FpvC were unsuccessful. In contrast, crystals of the FpvC-H6G mutant, which mimics the wild-type apo FpvC, led to reproducible crystals with good diffraction. This mutant with the hexahistidine 
involved in iron chelation replaced by hexaglycine is more stable than the wild-type apo FpvC, which may explain its crystallization success. The metal-induced structural rearrangement of the C-terminal domain to close the metal binding site can be illustrated by the comparison of free (mutant) and metalbound structures. Upon metal-binding, FpvC displays a very similar loss of secondary structure of the C-terminus of the inter-domain helix, as described for PsaA[29]. This helix initially proposed as rigid was thought to preclude large conformational motion. There are now two examples of cluster A-1 SBPs where a rather large conformational change of this helix can occur leading to a rigid-body movement of $13^{\circ}$ of the C-terminal domain of PsaA and to an internal rearrangement of the Cterminal domain up to $12.7 \AA$ in FpvC. Moreover, Radka and co-workers[18] suggest that structural rearrangement is required for metal loading and unloading in YfeA and its was shown that metal binding in TroA induces distinct conformational changes by circular dichroism and NMR[19]. Therefore, all characterized SBPs clusters[15] including cluster A are subject to conformational changes induced by ligand binding and present a diversity in conformational and dynamic plasticity [30].

\section{The physiological ligand of FpvC}

The protein calprotectin has been shown to be a polyspecific metal protein, able to bind $\mathrm{Mn}^{2+}, \mathrm{Ni}^{2+}$, $\mathrm{Zn}^{2+}$ and $\mathrm{Fe}^{2+}$ in the hexahistidine site[23, 31]. Its structure with a $\mathrm{Ni}^{2+}$ bound to the hexahistidine motif was reported as unique in 2017 among structurally characterized nickel proteins[23]. FpvC is now the second example. Using DSC and ITC, we showed that FpvC like calprotectin is polyspecific and can bind different divalent metal including $\mathrm{Fe}^{2+}, \mathrm{Mn}^{2+}, \mathrm{Ni}^{2+}$, and $\mathrm{Zn}^{2+}$. Unlike calprotectin which has a preference for $\mathrm{Ni}^{2+}$ over $\mathrm{Zn}^{2}$, FpvC displays the same affinity for $\mathrm{Ni}^{2+}, \mathrm{Zn}^{2+}$ and $\mathrm{Mn}^{2+}$ which is higher than that for $\mathrm{Fe}^{2+}$. This result seems not in agreement with the Irving-Williams series[23] $\left(\mathrm{Mg}^{2+}<\mathrm{Mn}^{2+}<\mathrm{Fe}^{2+}<\mathrm{Co}^{2+}<\mathrm{Ni}^{2+}<\mathrm{Cu}^{2+}<\mathrm{Zn}^{2+}\right)$ showing that in the case of $\mathrm{FpvC}, \mathrm{Mn}^{2+}$ and $\mathrm{Ni}^{2+}$ are thermodynamically favoured over $\mathrm{Zn}^{2+}$ for an octahedral coordination site. Nonetheless, $\mathrm{Fe}^{2+}$ and $\mathrm{Co}^{2+}$, which also favour octahedral geometry present a lower affinity compared with $\mathrm{Mn}^{2+}$. Therefore, other factors such as coordinating environment in terms of geometry, amino acids composition and

This article is protected by copyright. All rights reserved. 
flexibility offered by the metal-binding site may be important for metal specificity. However, in a biological context, the trend of the Irving-Williams series could break to acquire to true metal ligand $[32,33]$. Thus, in the context of FpvC, its interaction with other periplasmic proteins such as the SPB FpvF might be a critical control point.

Prior works on cluster A-1 SBPs (PsaA, ZnuA, TroA and the most recent on YfeA) showed that these proteins are also capable of interaction with a broad range of metal ions and thus appear to be polyselective[18-20, 29]. These reported metal binding properties emanate from experiments performed in vitro and often, raise the question: what is (are) the physiological ligand(s) of each SBP? Although FpvC can bind similarly and preferentially several divalent cations other than $\mathrm{Fe}^{2+}$ in vitro, it is likely dedicated to iron transport in vivo. Uptake experiments of PVD in complex with metals other than iron showed that these PVD-metal complexes do not accumulate and dissociate in $P$. aeruginosa cells. In contrast, they are expelled from the periplasm by the efflux system PvdRTOpmQ[34] showing that FpvC has probably access only to ferrous iron in P. aeruginosa periplasm. $f p v C$ gene and genes involved in iron acquisition by PVD belong to the PVD loci. Their transcription/expression is regulated by the intracellular iron concentration in P. aeruginosa cells and probably not by any other metal (Lopez et al., in Enviromn Microbiol under revision). When iron becomes limited, the sigma factors PvdS and FpvI activate the transcription of the PVD loci genes including $f p v C$ gene in order to produce PVD and express the proteins necessary to get access to iron via this siderophore[35]. On the opposite, in the presence of iron in excess, the transcriptional regulator Fur in complex with ferrous iron $\left(\mathrm{Fur}_{-} \mathrm{Fe}^{2+}\right)$ represses the expression of all these genes[35]. Moreover, a deletion of $f p v C$ affects iron acquisition by PVD[12]. Native mass spectrometry showed that FpvC interacts with the SBP FpvF (a ferrisiderophore SBP) as well as the FpvF-PVD-Fe complex[13]. Cross-linking approaches on P. aeruginosa cells incubated in the presence of PVD-Fe ${ }^{3+}$ confirmed the existence of such complexes in vivo. At last, in vitro PVD-Fe dissociation assays using DTT as an iron reducer and ferrozine as a ferrous iron chelator indicated that FpvC can like ferrozine chelate ferrous iron[12]. According to our current knowledge of this biological system, the PVD-Fe ${ }^{3+}$ 
complex is probably first scavenged by the FpvF-FpvC complex before iron reduction and dissociation from PVD[12, 13]. In such a mechanism, only iron can be reduced and transferred from PVD to FpvC.

Taken together, all these data in addition to the present EPR experiment and structural data clearly proof that in the mechanism of iron dissociation from PVD in the bacterial periplasm, ferric iron, after having been reduced by the inner membrane FpvG, is transferred from PVD to FpvC. The SBP FpvC brings then the ferrous ion to its associated $\mathrm{ABC}$ transporter for transport across the inner membrane into the cytoplasm. It is noteworthy that $\mathrm{Fe}^{2+}$ appears as the worst metal in terms of FpvC stability and affinity in vitro, probably to facilitate its release to the $\mathrm{ABC}$ transporter. This is in line with PsaA where the more tightly binding $\mathrm{Zn}^{2+}$ over-stabilises the SBP closed state, preventing transfer of the wrong metal to the transporter[29].

\section{Conclusion}

In conclusion, FpvC binds iron in its ferrous state and the octahedral metal site formed by six histidines stabilizes $\mathrm{Fe}^{2+}$ under aerobic conditions. Our work highlights, that the canonical metal site in FpvC is distinct from those described yet among cluster A-1 SBPs and that large structural changes can occur in this cluster. FpvC is also the first example of a SBP chelating siderophore free-ferrous iron, being involved in a siderophore-dependent iron uptake pathway. All other SBP previously described in such pathways were ferrisiderophore binding SBP, with a transport of ferrisiderophore complexes into the bacterial cytoplasm by the associated $\mathrm{ABC}$ transporter.

\section{Materials and methods}

Cloning, expression of mature His-tag FpvC and purification using a nickel column. The synthetic gene (Genscript) coding for the mature FpvC fused to a TEV protease cleavage site and a His-tag was inserted into pET-29a. E. coli BL21 pLysS were transformed by pET-29a-fpvC-tag. Cells

This article is protected by copyright. All rights reserved. 
were grown at $37^{\circ} \mathrm{C}$ in $\mathrm{LB}$ broth supplemented with $0.5 \mathrm{mM}$ isopropyl $\beta$-D-1-thiogalactopyranoside to induce protein production. Cells were centrifuged, resuspended in a buffer of $50 \mathrm{mM}$ Tris- $\mathrm{HCl}, \mathrm{pH}$ 8, $20 \mathrm{mM}$ imidazole and $300 \mathrm{mM} \mathrm{NaCl}$, and disrupted by sonication. After centrifugation at 25,000 $\mathrm{g}$ for $30 \mathrm{~min}$ at $4^{\circ} \mathrm{C}$, the supernatant was loaded onto a $5 \mathrm{ml}$ His-Trap column (GE Healthcare). Protein elution was performed with $50 \mathrm{mM}$ Tris- $\mathrm{HCl} \mathrm{pH} 8,300 \mathrm{mM}$ imidazole and $300 \mathrm{mM} \mathrm{NaCl}$. Protein fractions were loaded onto a gel filtration column (HiLoad 26/60 Superdex 200 prep grade, GE Healthcare) equilibrated with $50 \mathrm{mM}$ Tris- $\mathrm{HCl} \mathrm{pH} 8$ and $150 \mathrm{mM} \mathrm{NaCl}$. The protein fractions were pooled, concentrated at $19 \mathrm{mg} / \mathrm{ml}$ and stored at $-80^{\circ} \mathrm{C}$. This protocole leads to $\mathrm{FpvC}-\mathrm{Ni}^{2+}$ complex.

Cloning, expression and purification of His-tag FpvC-H6G mutant. Cloning, expression and purification of His-tag FpvC mutant (H77G, H102G, H147G, H213G, H235G and H286G) namely FpvC-H6G was performed as described previously[12].

Expression of mature His-tag FpvC under minimal media supplemented with iron and purification using an ion-exchange chromatography. E. coli BL21 transformed pLysS cells were grown at $37^{\circ} \mathrm{C}$ in $\mathrm{M} 9$ minimal medium supplemented with $4 \mu \mathrm{M} \mathrm{FeSO}{ }_{4}$ and one hour later with $1 \mathrm{mM}$ isopropyl $\beta$-D-1-thiogalactopyranoside to induce protein production. Cells were centrifuged, resuspended in a buffer of $20 \mathrm{mM}$ MES, pH 6.5, and disrupted by sonication. After centrifugation at $25,000 \mathrm{~g}$ for $30 \mathrm{~min}$ at $4^{\circ} \mathrm{C}$, the supernatant was loaded onto a cation-exchange chromatography (HiTrap SP 5ml, GE Healthcare). Protein elution was performed with a linear gradient of 0-1 M NaCl. Protein fractions were loaded onto a gel filtration column (HiLoad 26/60 Superdex 200 prep grade, GE Healthcare) equilibrated with $50 \mathrm{mM}$ Tris- $\mathrm{HCl} \mathrm{pH} 8$ and $150 \mathrm{mM} \mathrm{NaCl}$. The protein fractions were pooled, concentrated at $30 \mathrm{mg} / \mathrm{ml}$ and stored at $-80^{\circ} \mathrm{C}$. This protocole leads to $\mathrm{FpvC}-\mathrm{Fe}^{2+}$ complex.

This article is protected by copyright. All rights reserved. 
Removing of the His-tag and bound metal of FpvC. The C-terminal His-tag of pure mature FpvC was cleaved using recombinant TEV protease, which was incubated with the target protein at a mass ratio of $1: 30$ at $4^{\circ} \mathrm{C}$ for $12 \mathrm{~h}$. The protein was purified by applying a second step nickel column. The flow-through contained cleaved FpvC. FpvC was then concentrated and treated with $50 \mathrm{mM}$ ethylenediaminetetraacetic acid (EDTA) for $30 \mathrm{~min}$. Protein impurities were removed by gel filtration (HiLoad 26/60 Superdex 200 prep grade, GE Healthcare) equilibrated with $50 \mathrm{mM}$ Tris-HCl pH 8, 20 mM EDTA and $150 \mathrm{mM} \mathrm{NaCl}$. Preliminary data using DSC showed that FpvC was devoid of metal and could no longer bind metal likely due to the presence of EDTA. Because of poor yield of pure apo protein, a new synthetic gene was ordered coding for mature $\mathrm{FpvC}$ without any tag or artefact cloning.

\section{Cloning, expression and purification of apo FpvC devoid of any tag.}

The synthetic gene (Genscript) coding for the mature FpvC only was inserted into pET-29a. E. coli BL21 pLysS were transformed by pET-29a- $f p v C$. Cells were grown at $37^{\circ} \mathrm{C}$ in $\mathrm{LB}$ broth supplemented with $0.5 \mathrm{mM}$ isopropyl $\beta$-D-1-thiogalactopyranoside to induce protein production. Cells were centrifuged, resuspended in a buffer of $20 \mathrm{mM}$ MES, pH 6.5 and disrupted by sonication. After centrifugation at $25,000 \mathrm{~g}$ for $30 \mathrm{~min}$ at $4^{\circ} \mathrm{C}$, the supernatant was loaded onto a cation-exchange chromatography (HiTrap SP 5ml, GE Healthcare). Protein elution was performed with a linear gradient of $0-1 \mathrm{M} \mathrm{NaCl}$ and treated with $50 \mathrm{mM}$ EDTA for $30 \mathrm{~min}$. Protein impurities were further removed by gel filtration (HiLoad 26/60 Superdex 200 prep grade, GE Healthcare) equilibrated with $50 \mathrm{mM}$ Tris- $\mathrm{HCl} \mathrm{pH} 8,20 \mathrm{mM}$ EDTA and $150 \mathrm{mM} \mathrm{NaCl}$. A desalting column allowed EDTA removing using $50 \mathrm{mM}$ Tris- $\mathrm{HCl} \mathrm{pH} 8$ and $150 \mathrm{mM} \mathrm{NaCl}$. The protein fractions were pooled, concentrated at $15 \mathrm{mg} / \mathrm{ml}$ and stored at $-80^{\circ} \mathrm{C}$. This apo protein was used for CD, DSC, ITC and crystallization assays.

This article is protected by copyright. All rights reserved. 
Crystallization and structure determination. Crystallization conditions for metal-bound His-tag FpvC, FpvC-H6G mutant and apo FpvC were screened using QIAGEN kits (Valencia, CA) with a Mosquito nanodrop robot (Genomic solutions). Metal-bound His-tag FpvC and FpvC-H6G crystals were manually optimized (Table 1). Crystals were transferred to a cryo-protectant solution (mother liquor supplemented with $25 \%$ PEG 400 or ethylene glycol) and flash-frozen in liquid nitrogen. Diffraction data were collected at $100 \mathrm{~K}$ on PROXIMA 1 and 2 beamlines at SOLEIL synchrotron (Saint-Aubin, France). Data processing was performed using the XDS package[36] (Table 1). The first structure was determined at $2.4 \AA$ resolution by SAD method at the peak absorption energy of nickel. The presence of a fortuitous nickel in crystals was found thanks to an X-ray fluorescence emission scan on the beamline. The steps of nickel ion substructure determination, phases calculation and density modification were performed using CRANK from CCP4 (Collaborative Computational Project, Number 4) and a partial model was built using BUCCANEER (CCP4). This model was then used to calculate the phases of a high resolution dataset at $1.65 \AA$ resolution leading to the complete polypeptide chain model except the loop region 132-141. The other structures were determined by molecular replacement with PHASER[37] using the first refined structure of FpvC as a search model. Because of the anisotropy of the diffraction of $\mathrm{FpvC}_{-} \mathrm{Fe}^{2+}$ and FpvC-H6G mutant crystals, the DEBYE and STARANISO programs developed by Global phasing Ltd were applied to the data scaled with AIMLESS using the STARANISO server (http://staraniso.globalphasing.or/). These programs perform an anisotropic cut-off of merge intensity data on the basis of an analysis of local $I / \sigma(I)$, compute Bayesian estimates of structures amplitudes, taking into account their anisotropic falloff, and apply an anisotropic correction to the data. The corrected anisotropic amplitudes were used for further refinement. Refinement of each structure was performed with BUSTER-2.10[38], employing TLS groups and NCS restraints when more than one molecule was present in the asymmetric unit. Inspection of the density maps and manual rebuilding were performed using COOT[39]. Refinement details of each structure are shown in Table 1. Molecular graphics images were generated using PyMOL (http://www.pymol.org).

This article is protected by copyright. All rights reserved. 
Electron paramagnetic resonance (EPR) measurement. X-band cw-EPR spectra were recorded with a Bruker Elexsys 500 X-band spectrometer equipped with a standard ER 4102 (Bruker) X-band resonator, a Bruker teslameter, an Oxford Instruments cryostat (ESR 900) and an Oxford ITC504 temperature controller. Samples of the purified His-tag FpvC-Fe complex at $50 \mu \mathrm{M}$ in MES pH 6.5 or $60 \mu \mathrm{M}$ in Tris $\mathrm{pH} 8(\approx 150 \mu \mathrm{L})$ loaded in EPR tubes were frozen in an ethanol bath cooled down at $198 \mathrm{~K}$ with dry ice and then transferred in liquid nitrogen. Potassium ferricyanure was added at 30 and $60 \mu \mathrm{M}$.

Circular dichroism experiments (CD). Circular dichroïsm in the far-UV region was performed using a spectropolarimeter (Jasco J-810) equipped with a water-cooled Peltier unit (Jasco circular dichroïsm spectrometer model J810). Apo FpvC and FpvC-H6G mutant were both concentrated at $250 \mu \mathrm{M}$ in $50 \mathrm{mM}$ Tris $\mathrm{pH} 8$ and $150 \mathrm{mM} \mathrm{NaCl}$. Spectra were recorded in a cell width of $0.01-\mathrm{mm}$ path length (121.QS, Hellma) from 185 to $260 \mathrm{~nm}$ at $20^{\circ} \mathrm{C}$. Six consecutive scans from each sample were merged to produce an averaged spectrum; the spectra were corrected using buffer baselines measured under the same conditions. Data were recorded in mdeg and converted using the mean residues ellipticity method $\left(\mathrm{deg} . \mathrm{cm}^{2} \mathrm{~mol}^{-1}\right)$. Secondary structure estimates were derived from the normalized spectra using the CDSSTR, SELCON3, CONTIN of the DICHROWEB server[40, 41].

Differential scanning calorimetry (DSC). Thermal stability of the apo form, bound-metal FpvC as well as the FpvC-H6G mutant was performed by DSC on a MicroCal model VP-DSC in a standard buffer with $30 \mu \mathrm{M}$ and $300 \mu \mathrm{M}$ for protein and metal, respectively. Divalent metals used were $\mathrm{MgSO}_{4}, \quad \mathrm{MnCl}_{2}, \mathrm{CaCl}_{2}, \mathrm{NiSO}_{4}, \mathrm{CuCl}_{2}, \mathrm{CoCl}_{2}, \mathrm{CdCl}_{2}, \mathrm{ZnSO}_{4}, \mathrm{FeSO}_{4}$ and $1 \mathrm{mM}$ Tris(2carboxyethyl)phosphine) (TCEP), $\mathrm{FeCl}_{3}, \mathrm{FeCl}_{3}$ and $1 \mathrm{mM}$ TCEP; TCEP being a reductant agent. Each measurement was preceded by a baseline scan with the standard buffer. All solutions were degassed just before loading into the calorimeter. Scans were performed at $1 \mathrm{~K} \cdot \mathrm{min}^{-1}$ between 20 and $90^{\circ} \mathrm{C}$. The 
heat capacity of the buffer was subtracted from that of the protein sample before analysis.

Thermodynamic parameters were determined by fitting the data to the following equation:

$\Delta C_{p}(T)=\frac{K_{d}(T) \Delta H_{c a l} \Delta H_{v H}}{\left[1+K_{d}(T)\right]^{2} R T^{2}}$

where $K \mathrm{~d}$ is the equilibrium constant for a two-state process, $\Delta H v \mathrm{vh}$ is the enthalpy calculated on the basis of a two-state process and $\Delta H c$ cal is the measured enthalpy.

Isothermal titration microcalorimetry measurements (ITC). Isothermal titration microcalorimetry experiments were performed with an ITC200 isothermal titration calorimeter from MicroCal (Malvern). The experiments were carried out at $20^{\circ} \mathrm{C}$. Protein concentration in the microcalorimeter cell $(0.2 \mathrm{ml})$ was $35 \mu \mathrm{M}$. Nineteen injections of $2 \mu \mathrm{l}$ metal at concentrations ranging from 600 to 750 $\mu \mathrm{M}$ were performed at intervals of $180 \mathrm{~s}$ while stirring at $500 \mathrm{rpm}$. The experimental data were fitted to theoretical titration curves with software supplied by MicroCal $\left(\right.$ ORIGIN $\left.^{\circledR}\right)$. This software uses the relationship between the heat generated by each injection and $\Delta \mathrm{H}$ (enthalpy change in $\mathrm{Kcal} / \mathrm{Mol}), K_{a}$ (the association binding constant in $\mathrm{M}^{-1}$ ), $\mathrm{n}$ (the number of binding sites), total protein concentration and free and total ligand concentrations[42].

\section{References}

1. Lyczak, J. B., Cannon, C. L. \& Pier, G. B. (2000) Establishment of Pseudomonas aeruginosa infection: lessons from a versatile opportunist, Microbes Infect. 2, 1051-60.

2. Boukhalfa, H. \& Crumbliss, A. L. (2002) Chemical aspects of siderophore mediated iron transport, Biometals. 15, 325-39.

3. Schalk, I. J., Mislin, G. L. \& Brillet, K. (2012) Structure, function and binding selectivity and stereoselectivity of siderophore-iron outer membrane transporters, Curr Top Membr. 69, 37-66.

4. Schalk, I. J. \& Guillon, L. (2013) Fate of ferrisiderophores after import across bacterial outer membranes: different iron release strategies are observed in the cytoplasm or periplasm depending on the siderophore pathways, Amino Acids. 44, 1267-77.

5. Schalk, I. J. \& Guillon, L. (2013) Pyoverdine biosynthesis and secretion in Pseudomonas aeruginosa: implications for metal homeostasis, Environ Microbiol. 15, 1661-73.

6. Poole, K., Neshat, S., Krebes, K. \& Heinrichs, D. E. (1993) Cloning and nucleotide sequence analysis of the ferripyoverdine receptor gene fpvA of Pseudomonas aeruginosa, J Bacteriol. 175, 4597-604.

This article is protected by copyright. All rights reserved. 
7. Ghysels, B., Dieu, B. T., Beatson, S. A., Pirnay, J. P., Ochsner, U. A., Vasil, M. L. \& Cornelis, P. (2004) FpvB, an alternative type I ferripyoverdine receptor of Pseudomonas aeruginosa, Microbiology. 150, 1671-80.

8. Brillet, K., Journet, L., Celia, H., Paulus, L., Stahl, A., Pattus, F. \& Cobessi, D. (2007) A beta strand lock exchange for signal transduction in TonB-dependent transducers on the basis of a common structural motif, Structure. 15, 1383-91.

9. Schalk, I. J., Abdallah, M. A. \& Pattus, F. (2002) Recycling of pyoverdin on the FpvA receptor after ferric pyoverdin uptake and dissociation in Pseudomonas aeruginosa, Biochemistry. 41, 1663-71. 10. Greenwald, J., Hoegy, F., Nader, M., Journet, L., Mislin, G. L., Graumann, P. L. \& Schalk, I. J. (2007) Real time fluorescent resonance energy transfer visualization of ferric pyoverdine uptake in Pseudomonas aeruginosa. A role for ferrous iron, J Biol Chem. 282, 2987-95.

11. Yeterian, E., Martin, L. W., Lamont, I. L. \& Schalk, I. J. (2010) An efflux pump is required for siderophore recycling by Pseudomonas aeruginosa, Environ Microbiol Rep. 2, 412-8.

12. Ganne, G., Brillet, K., Basta, B., Roche, B., Hoegy, F., Gasser, V. \& Schalk, I. J. (2017) Iron Release from the Siderophore Pyoverdine in Pseudomonas aeruginosa Involves Three New Actors: FpvC, FpvG, and FpvH, ACS Chem Biol. 12, 1056-1065.

13. Brillet, K., Ruffenach, F., Adams, H., Journet, L., Gasser, V., Hoegy, F., Guillon, L., Hannauer, M., Page, A. \& Schalk, I. J. (2012) An ABC transporter with two periplasmic binding proteins involved in iron acquisition in Pseudomonas aeruginosa, ACS Chem Biol. 7, 2036-45.

14. Lee, Y. H., Deka, R. K., Norgard, M. V., Radolf, J. D. \& Hasemann, C. A. (1999) Treponema pallidum TroA is a periplasmic zinc-binding protein with a helical backbone, Nat Struct Biol. 6, 62833.

15. Berntsson, R. P., Smits, S. H., Schmitt, L., Slotboom, D. J. \& Poolman, B. (2010) A structural classification of substrate-binding proteins, FEBS Lett. 584, 2606-17.

16. Sigfridsson, K. G., Chernev, P., Leidel, N., Popovic-Bijelic, A., Graslund, A. \& Haumann, M. (2013) Rapid X-ray photoreduction of dimetal-oxygen cofactors in ribonucleotide reductase, $J$ Biol Chem. 288, 9648-61.

17. Peisach, J., Blumberg, W. E., Lode, E. T. \& Coon, M. J. (1971) An analysis of the electron paramagnetic resonance spectrum of pseudomonas oleovorans rubredoxin. A method for determination of the liganids of ferric iron in completely rhombic sites, J Biol Chem. 246, 5877-81.

18. Radka, C. D., DeLucas, L. J., Wilson, L. S., Lawrenz, M. B., Perry, R. D. \& Aller, S. G. (2017) Crystal structure of Yersinia pestis virulence factor YfeA reveals two polyspecific metal-binding sites, Acta Crystallogr D Struct Biol. 73, 557-572.

19. Zheng, B., Zhang, Q., Gao, J., Han, H., Li, M., Zhang, J., Qi, J., Yan, J. \& Gao, G. F. (2011) Insight into the interaction of metal ions with TroA from Streptococcus suis, PLoS One. 6, e19510.

20. Yatsunyk, L. A., Easton, J. A., Kim, L. R., Sugarbaker, S. A., Bennett, B., Breece, R. M., Vorontsov, II, Tierney, D. L., Crowder, M. W. \& Rosenzweig, A. C. (2008) Structure and metal binding properties of ZnuA, a periplasmic zinc transporter from Escherichia coli, J Biol Inorg Chem. 13, 271-88.

21. Sun, X., Baker, H. M., Ge, R., Sun, H., He, Q. Y. \& Baker, E. N. (2009) Crystal structure and metal binding properties of the lipoprotein MtsA, responsible for iron transport in Streptococcus pyogenes, Biochemistry. 48, 6184-90.

22. Damo, S. M., Kehl-Fie, T. E., Sugitani, N., Holt, M. E., Rathi, S., Murphy, W. J., Zhang, Y., Betz, C., Hench, L., Fritz, G., Skaar, E. P. \& Chazin, W. J. (2013) Molecular basis for manganese sequestration by calprotectin and roles in the innate immune response to invading bacterial pathogens, Proc Natl Acad Sci U S A. 110, 3841-6.

23. Nakashige, T. G., Zygiel, E. M., Drennan, C. L. \& Nolan, E. M. (2017) Nickel Sequestration by the Host-Defense Protein Human Calprotectin, J Am Chem Soc. 139, 8828-8836.

24. Srivastava, S. S., Jamkhindikar, A. A., Raman, R., Jobby, M. K., Chadalawada, S., Sankaranarayanan, R. \& Sharma, Y. (2017) A Transition Metal-Binding, Trimeric betagammaCrystallin from Methane-Producing Thermophilic Archaea, Methanosaeta thermophila, Biochemistry. 56, 1299-1310.

25. Browning, C., Shneider, M. M., Bowman, V. D., Schwarzer, D. \& Leiman, P. G. (2012) Phage pierces the host cell membrane with the iron-loaded spike, Structure. 20, 326-39.

This article is protected by copyright. All rights reserved. 
26. Bartual, S. G., Otero, J. M., Garcia-Doval, C., Llamas-Saiz, A. L., Kahn, R., Fox, G. C. \& van Raaij, M. J. (2010) Structure of the bacteriophage T4 long tail fiber receptor-binding tip, Proc Natl Acad Sci U S A. 107, 20287-92.

27. Koc, C., Xia, G., Kuhner, P., Spinelli, S., Roussel, A., Cambillau, C. \& Stehle, T. (2016) Structure of the host-recognition device of Staphylococcus aureus phage varphi11, Sci Rep. 6, 27581.

28. Carver, G., Tregenna-Piggott, P. L., Barra, A. L., Neels, A. \& Stride, J. A. (2003) Spectroscopic and structural characterization of the [Fe(imidazole)(6)](2+) cation, Inorg Chem. 42, 5771-7.

29. Counago, R. M., Ween, M. P., Begg, S. L., Bajaj, M., Zuegg, J., O'Mara, M. L., Cooper, M. A., McEwan, A. G., Paton, J. C., Kobe, B. \& McDevitt, C. A. (2014) Imperfect coordination chemistry facilitates metal ion release in the Psa permease, Nat Chem Biol. 10, 35-41.

30. de Boer, M., Gouridis, G., Vietrov, R., Begg, S. L., Schuurman-Wolters, G. K., Husada, F., Eleftheriadis, N., Poolman, B., McDevitt, C. A. \& Cordes, T. (2019) Conformational and dynamic plasticity in substrate-binding proteins underlies selective transport in ABC importers, Elife. 8.

31. Nakashige, T. G. \& Nolan, E. M. (2017) Human calprotectin affects the redox speciation of iron, Metallomics. 9, 1086-1095.

32. Dudev, T. \& Lim, C. (2008) Metal binding affinity and selectivity in metalloproteins: insights from computational studies, Annu Rev Biophys. 37, 97-116.

33. Waldron, K. J., Rutherford, J. C., Ford, D. \& Robinson, N. J. (2009) Metalloproteins and metal sensing, Nature. 460, 823-30.

34. Hannauer, M., Braud, A., Hoegy, F., Ronot, P., Boos, A. \& Schalk, I. J. (2012) The PvdRTOpmQ efflux pump controls the metal selectivity of the iron uptake pathway mediated by the siderophore pyoverdine in Pseudomonas aeruginosa, Environ Microbiol. 14, 1696-708.

35. Visca, P., Leoni, L., Wilson, M. J. \& Lamont, I. L. (2002) Iron transport and regulation, cell signalling and genomics: lessons from Escherichia coli and Pseudomonas, Mol Microbiol. 45, 1177 90.

36. Kabsch, W. (2010) Xds, Acta Crystallogr D Biol Crystallogr. 66, 125-32.

37. McCoy, A. J., Grosse-Kunstleve, R. W., Adams, P. D., Winn, M. D., Storoni, L. C. \& Read, R. J. (2007) Phaser crystallographic software, J Appl Crystallogr. 40, 658-674.

38. Blanc, E., Roversi, P., Vonrhein, C., Flensburg, C., Lea, S. M. \& Bricogne, G. (2004) Refinement of severely incomplete structures with maximum likelihood in BUSTER-TNT, Acta Crystallogr D Biol Crystallogr. 60, 2210-21.

39. Emsley, P. \& Cowtan, K. (2004) Coot: model-building tools for molecular graphics, Acta Crystallogr D Biol Crystallogr. 60, 2126-32.

40. Sreerama, N. \& Woody, R. W. (2000) Estimation of protein secondary structure from circular dichroism spectra: comparison of CONTIN, SELCON, and CDSSTR methods with an expanded reference set, Anal Biochem. 287, 252-60.

41. Whitmore, L. \& Wallace, B. A. (2004) DICHROWEB, an online server for protein secondary structure analyses from circular dichroism spectroscopic data, Nucleic Acids Res. 32, W668-73.

42. Wiseman, T., Williston, S., Brandts, J. F. \& Lin, L. N. (1989) Rapid measurement of binding constants and heats of binding using a new titration calorimeter, Anal Biochem. 179, 131-7.

This article is protected by copyright. All rights reserved. 
Table 1. Crystallographic data and refinement parameters

\begin{tabular}{|c|c|c|c|c|c|c|}
\hline & FpvC-Ni ${ }^{2+}$ & FpvC-Ni ${ }^{2+}$ & FpvC-Ni ${ }^{2+}$ & $\mathrm{FpvC}_{-\mathrm{Fe}^{2+}}$ & FpvC-Mn ${ }^{2+}$ & \begin{tabular}{|l|} 
FpvC-H6G \\
Mutant
\end{tabular} \\
\hline PDB code & $\begin{array}{l}\text { SAD } \\
\text { phasing }\end{array}$ & 6R3Z & 6R44 & 6R5S & 6RU4 & 6R6K \\
\hline Crystallization & $16-18 \% \mathrm{PE}$ & $\mathrm{G} 6 \mathrm{~K}, 0.1 \mathrm{M}$ & MES pH 6.5 & & & $\begin{array}{l}\text { 8\% } \\
\text { MES }\end{array}$ \\
\hline $\begin{array}{l}\text { Number of molecules } \\
\text { in } \\
\text { asymmetric unit }\end{array}$ & & 1 & 2 & 2 & 4 & 2 \\
\hline Wavelength $(\AA)$ & 1.48480 & 0.98 & 1.48480 & 1.73867 & 0.98 & 0.98 \\
\hline \begin{tabular}{|l|} 
Space group \\
Cell parameters $\left(\AA,{ }^{\circ}\right)$
\end{tabular} & $\begin{array}{l}P 2_{1} 2_{1} 2_{1} \\
a=43.5 \\
b=63.1 \\
c=90.4\end{array}$ & $\begin{array}{l}P 2_{1} 2_{1} 2_{1} \\
a=43.6 \\
b=62.7 \\
c=90.5\end{array}$ & $\begin{array}{l}P 2_{1} \\
a=66.8 \\
b=41.4 \\
c=104.5 \\
\beta=96 .\end{array}$ & $\begin{array}{l}l 2 \\
a=72 \\
b=44.2 \\
c=179.8 \\
\beta=95.1\end{array}$ & \begin{tabular}{|l}
$P 2_{1}$ \\
$a=44.0$ \\
$b=178.3$ \\
$c=66.8$ \\
$\beta=90.6$
\end{tabular} & 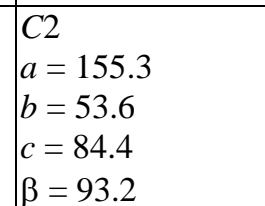 \\
\hline Resolution $(\AA)$ & $\begin{array}{l}50-2.4 \\
(2.46-2.4)\end{array}$ & $\begin{array}{l}39.2-1.65 \\
(1.75-1.65)\end{array}$ & $\begin{array}{l}43.2-1.99 \\
(2.05-1.99)\end{array}$ & $\begin{array}{l}37.62-2.75 \\
(2.88-2.75)\end{array}$ & $\begin{array}{l}44.57-2.49 \\
(2.64-2.49)\end{array}$ & $\begin{array}{l}43.74-2.1 \\
(2.15-2.1)\end{array}$ \\
\hline \begin{tabular}{|l|l|}
$\begin{array}{l}\text { No. of } \\
\text { reflections }\end{array}$ & observed \\
\end{tabular} & $\begin{array}{l}593452 \\
(44210)\end{array}$ & $\begin{array}{l}306200 \\
(32265) \\
\end{array}$ & $\begin{array}{l}227822 \\
(8580)\end{array}$ & $\begin{array}{l}96186 \\
(11989) \\
\end{array}$ & $\begin{array}{l}243884 \\
(35930)\end{array}$ & $\begin{array}{l}284413 \\
(45679)\end{array}$ \\
\hline $\begin{array}{l}\text { No. of unique } \\
\text { reflections }\end{array}$ & $\begin{array}{l}18809 \\
(1377)\end{array}$ & $\begin{array}{l}30063 \\
(4251)\end{array}$ & $\begin{array}{l}38967 \\
(2567)\end{array}$ & $\begin{array}{l}14604 \\
(1849)\end{array}$ & $\begin{array}{l}35191 \\
(5188)\end{array}$ & $\begin{array}{l}40831 \\
(6474)\end{array}$ \\
\hline$R_{\text {sym }}(\%)$ & $\begin{array}{l}17.9 \\
(79.3)\end{array}$ & $\begin{array}{l}11 \\
(122.9)\end{array}$ & $\begin{array}{l}16.1 \\
(107.1)\end{array}$ & $\begin{array}{l}12.2 \\
(130)\end{array}$ & $\begin{array}{l}17 \\
(128.1)\end{array}$ & $\begin{array}{l}10.6 \\
(320.6)\end{array}$ \\
\hline$R_{\mathrm{pim}}$ & $3.2(24.6)$ & $5.1(72)$ & $11.2(85.5)$ & $7.8(83)$ & $7(53.3)$ & $4.3(141)$ \\
\hline Completeness (\%) & $\begin{array}{l}100 \\
(99)\end{array}$ & \begin{tabular}{|l|}
97.8 \\
$(86.7)$
\end{tabular} & $\begin{array}{l}98.8 \\
(88.5)\end{array}$ & $\begin{array}{l}97.2 \\
(93.7)\end{array}$ & \begin{tabular}{|l|}
98.4 \\
$(90.1)$
\end{tabular} & $\begin{array}{l}99.7 \\
(98.3)\end{array}$ \\
\hline$I / \sigma(I)$ & $\begin{array}{l}21.6 \\
(5.64)\end{array}$ & $\begin{array}{l}12.8 \\
(1.2)\end{array}$ & $\begin{array}{l}6.13 \\
(1)\end{array}$ & $\begin{array}{l}9.35 \\
(1.06)\end{array}$ & \begin{tabular}{|l|}
8.58 \\
$(1.35)$
\end{tabular} & $\begin{array}{l}9.12 \\
(0.42)\end{array}$ \\
\hline $\mathrm{CC}_{1 / 2}$ & $\begin{array}{l}99.9 \\
(96.4)\end{array}$ & $\mid \begin{array}{l}99.7 \\
(82.8)\end{array}$ & $\begin{array}{l}99.1 \\
(54.4)\end{array}$ & $\begin{array}{l}99.5 \\
(66.8)\end{array}$ & $\mid \begin{array}{l}99.6 \\
(54.1)\end{array}$ & \begin{tabular}{|l}
99.9 \\
$(49.4)$
\end{tabular} \\
\hline$R_{\text {cryst }}(\%)$ & & 18.4 & 19.5 & 18.9 & 19.6 & 19.4 \\
\hline$R_{\text {free }}(\%)$ & & 21.9 & 22.6 & 24.2 & 23.8 & 23.4 \\
\hline $\begin{array}{l}\text { RMSD } \text { bond lengths } \\
(\AA)\end{array}$ & & 0.01 & 0.01 & 0.01 & 0.01 & 0.01 \\
\hline RMDS bond angles $\left(^{\circ}\right)$ & & 0.97 & 1.1 & 1.17 & 1.16 & 1.13 \\
\hline $\begin{array}{l}\text { Average } B\left(\AA^{2}\right) \\
\text { Protein } \mathrm{A} / \mathrm{B} / \mathrm{C} / \mathrm{D} \\
\text { Metal A/B/C/D } \\
\text { solvent }\end{array}$ & & $\begin{array}{l}30.5 \\
22.6 \\
41.0\end{array}$ & $\begin{array}{l}39.1 / 44.4 \\
24.3 / 27.1 / \\
40.2\end{array}$ & $\begin{array}{l}54.8 / 59.8 \\
53.2 / 51.6 \\
43.8 \\
\end{array}$ & $\begin{array}{l}59.7 / 73.8 / 58 / 65.1 \\
43 / 51.4 / 44.8 / 49 \\
52.1 \\
\end{array}$ & $\begin{array}{l}46 / 132.1 \\
50.9\end{array}$ \\
\hline $\begin{array}{l}\text { Clashscore }^{\mathrm{a}} \\
\text { MolProbity score }^{\mathrm{a}}\end{array}$ & & $\begin{array}{l}1.17 \\
0.89\end{array}$ & $\begin{array}{l}2.0 \\
1.63\end{array}$ & $\begin{array}{l}4.58 \\
2.23\end{array}$ & $\begin{array}{l}3.48 \\
1.87\end{array}$ & $\begin{array}{l}4.79 \\
2\end{array}$ \\
\hline \begin{tabular}{|l|} 
Ramachandran plot (\%) \\
Favoured \\
Allowed \\
Outliers \\
\end{tabular} & & $\begin{array}{l}97.7 \\
2.3 \\
0\end{array}$ & $\begin{array}{l}97.55 \\
2.55 \\
0.19 \\
\end{array}$ & $\begin{array}{l}95.3 \\
4.51 \\
0.19 \\
\end{array}$ & $\begin{array}{l}96.33 \\
3.29 \\
0.38 \\
\end{array}$ & \begin{tabular}{|l}
96.5 \\
3.5 \\
0 \\
\end{tabular} \\
\hline
\end{tabular}

This article is protected by copyright. All rights reserved. 
Values for the highest resolution shell are in parentheses. $\mathrm{CC}_{1 / 2}=$ percentage of correlation between intensities from random half-dataset. ${ }^{a}$ Calculated with MolProbity

Table 2. Distances $(\AA)$ between metal ion and histidine (His) in metal-bound FpvC structures

\begin{tabular}{|l|l|l|l|l|l|l|}
\hline & His77 & His102 & His147 & His213 & His235 & His286 \\
\hline $\mathbf{N i}^{2+}$ in P2 $\mathbf{2}_{1} \mathbf{2}_{1}$ & 2.19 & 2.27 & 2.20 & 2.18 & 2.15 & 2.20 \\
\hline $\begin{array}{l}\mathbf{N i}^{2+} \text { in P2 } \\
(\mathbf{m o l} \mathbf{A})\end{array}$ & 2.13 & 2.24 & 2.17 & 2.11 & 2.14 & 2.25 \\
\hline $\begin{array}{l}\mathbf{N i}^{2+} \text { in P2 } \\
(\mathbf{m o l} \mathbf{B})\end{array}$ & 2.17 & 2.17 & 2.17 & 2.11 & 2.16 & 2.24 \\
\hline $\mathbf{F e}^{2+}(\mathbf{m o l} \mathbf{A})$ & 2.27 & 2.44 & 2.22 & 2.37 & 2.13 & 2.27 \\
\hline $\mathbf{F e}^{2+}(\mathbf{m o l ~ B})$ & 2.26 & 2.37 & 2.18 & 2.39 & 2.19 & 2.20 \\
\hline $\mathbf{M n}^{2+}(\mathbf{m o l} \mathbf{A})$ & 2.49 & 2.42 & 2.26 & 2.28 & 2.21 & 2.25 \\
\hline $\mathbf{M n}^{2+}(\mathbf{m o l} \mathbf{B})$ & 2.46 & 2.46 & 2.36 & 2.30 & 2.15 & 2.29 \\
\hline $\mathbf{M n}^{2+}(\mathbf{m o l ~ C})$ & 2.42 & 2.45 & 2.28 & 2.30 & 2.22 & 2.23 \\
\hline $\mathbf{M n}^{2+}(\mathbf{m o l} \mathbf{D})$ & 2.45 & 2.47 & 2.29 & 2.31 & 2.14 & 2.28 \\
\hline
\end{tabular}

Table 3. Secondary structure estimations from CD experiments

\begin{tabular}{ccc}
\hline & Apo FpvC & FpvC-H6G mutant \\
\hline $\boldsymbol{\alpha}$-helices & $53 \%$ & $51 \%$ \\
$\boldsymbol{\beta}$-sheets & $16 \%$ & $17 \%$ \\
Random coil & $31 \%$ & $32 \%$ \\
\hline
\end{tabular}

This article is protected by copyright. All rights reserved. 
Table 4. Melting temperature of purified apo FpvC (no tag) and FpvC-H6G mutant and effect of metal ions

\begin{tabular}{|c|c|c|c|}
\hline Protein & $\operatorname{Tm}\left({ }^{\circ} \mathbf{C}\right)$ & $\Delta \operatorname{Tm}\left({ }^{\circ} \mathrm{C}\right)$ & $\Delta H\left(\mathrm{Kcal} / \mathrm{mol} /{ }^{\circ} \mathrm{C}\right)$ \\
\hline Apo FpvC & $58.96 \pm 0.002$ & & 104 \\
\hline Apo FpvC + EDTA & $58.97 \pm 0.002$ & & 103 \\
\hline Apo FpvC + TCEP & $58.64 \pm 0.002$ & & 97 \\
\hline FpvC-H6G mutant & $62.23 \pm 0.002$ & $\sim 3$ & 139 \\
\hline Apo FpvC + $\mathrm{Fe}^{2+}+$ TCEP & $65.62 \pm 0.01$ & $\sim 7$ & 102 \\
\hline $\mathrm{Apo} \mathrm{FpvC}+\mathrm{Fe}^{2+}\left(\mathrm{FeSO}_{4}\right)$ & $63.95 \pm 0.03$ & $\sim 5$ & 94 \\
\hline Apo $\mathrm{FpvC}+\mathrm{Fe}^{3+}\left(\mathrm{FeCl}_{3}\right)$ & $57.71 \pm 0.01$ & 0 & 72 \\
\hline Apo $\mathrm{FpvC}+\mathrm{Fe}^{3+}+$ TCEP & $\begin{array}{l}2 \text { peaks: } 58.67 \pm 0.006 \text { and } 64.54 \pm \\
0.008\end{array}$ & 0 and $\sim 6$ & 64 and 42 \\
\hline Apo $\mathrm{FpvC}+\mathrm{Mg}^{2+}\left(\mathrm{MgCl}_{2}\right)$ & $70.12 \pm 0.01$ & $\sim 11$ & 120 \\
\hline Apo $\mathrm{FpvC}+\mathrm{Ca}^{2+}\left(\mathrm{CaCl}_{2}\right)$ & $72.62 \pm 0.009$ & $\sim 14$ & 134 \\
\hline Apo $\mathbf{F p v C}+\mathbf{N i}^{2+}\left(\mathrm{NiSO}_{4}\right)$ & $86.39 \pm 0.009$ & $\sim 27$ & 176 \\
\hline Apo $\mathrm{FpvC}+\mathrm{Zn}^{2+}\left(\mathrm{ZnSO}_{4}\right)$ & $85.27 \pm 0.01$ & $\sim 26$ & 164 \\
\hline Apo $\mathrm{FpvC}+\mathrm{Mn}^{2+}\left(\mathrm{MnCl}_{2}\right)$ & $85.73 \pm 0.01 ;(66.80)$ & $\sim 27$ & 157 \\
\hline $\mathrm{Apo} \mathrm{FpvC}+\mathrm{Co}^{2+}\left(\mathrm{CoCl}_{2}\right)$ & $\begin{array}{l}2 \text { peaks: } 75.43 \pm 0.008 \text { and } 86.30 \pm \\
0.02\end{array}$ & $\begin{array}{l}\sim 16 \text { and } \\
\sim 27\end{array}$ & 116 and 31 \\
\hline Apo $\mathrm{FpvC}+\mathrm{Cu}^{2+}\left(\mathrm{CuCl}_{2}\right)$ & $\begin{array}{l}2 \text { peaks: } 75.76 \pm 0.01 \text { and } 85.12 \pm \\
0.008\end{array}$ & $\begin{array}{l}\sim 17 \text { and } \\
\sim 26\end{array}$ & 81 and 65 \\
\hline Apo $\mathrm{FpvC}+\mathrm{Cd}^{2+}\left(\mathrm{CdCl}_{2}\right)$ & $\begin{array}{l}2 \text { peaks: } 75.19 \pm 0.007 \text { and } 85.07 \pm \\
0.02\end{array}$ & $\begin{array}{l}\sim 16 \text { and } \\
\sim 26\end{array}$ & 98 and 27 \\
\hline \multicolumn{4}{|l|}{ 更 } \\
\hline Apo $\mathrm{FpvC}+\mathrm{Ni}^{2+}+$ EDTA & $58.97 \pm 0.002$ & & 104 \\
\hline Apo $\mathrm{FpvC}+\mathrm{Zn}^{2+}+$ EDTA & $58.96 \pm 0.002$ & & 103 \\
\hline
\end{tabular}

This article is protected by copyright. All rights reserved. 
Accession numbers. The atomic coordinates and structure factors have been deposited at the Protein Data Bank under PDB ID 6R3Z and 6R44 for FpvC with $\mathrm{Ni}^{2+}$ in $\mathrm{P} 2{ }_{1} 2_{1} 2_{1}$ and $\mathrm{P} 2_{1}$, respectively, $\mathrm{PDB}$ ID 6R5S for FpvC with $\mathrm{Fe}^{2+}$, PDB ID 6RU4 with $\mathrm{Mn}^{2+}$ and PDB ID 6R6K for FpvC-H6G mutant.

Acknowledgements. This work benefited from the I2BC crystallization and microcalorimetry platforms supported by FRISBI ANR-10-INSB-05-01. We acknowledge SOLEIL for provision of synchrotron radiation facilities (proposals ID 20130869, 20140774, 20150780 and 20170872) in using PROXIMA 1 and 2 beamlines and we thank all the staff for assistance in using the beamlines. We are grateful to Drs. Davy Martin and Human Rezaei (INRA, VIM-UR0892, Jouy-en-Josas) for access to their CD equipment. We thank Dr. Nadine Assrir (ICSN, Gif sur Yvette) for help in CD data processing.

Author contributions. AV, LM, LLB and SM performed all the crystallography work. MAN and AB performed the microcalorimetry and EPR experiments, respectively. PL performed STARANISO analysis. KB and IS provide the plasmids and expertise in FpvC system. SM wrote the manuscript. All the authors discussed the results and contributed to the writing of the manuscript.

Declarations of interest: none

This article is protected by copyright. All rights reserved. 


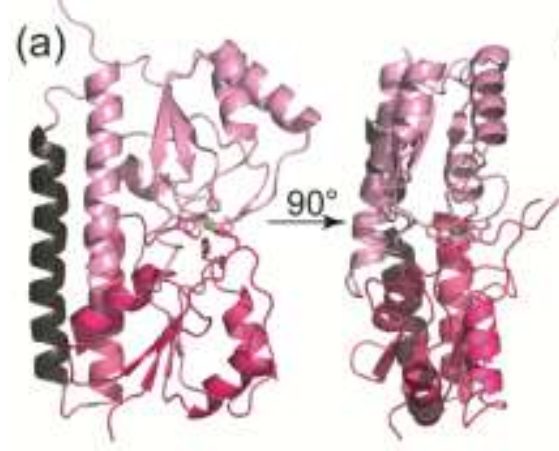

(d)

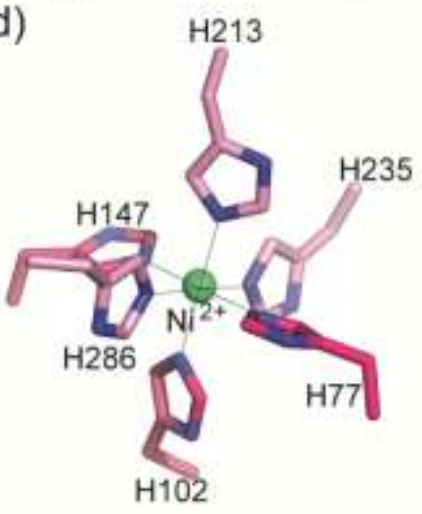

(b)

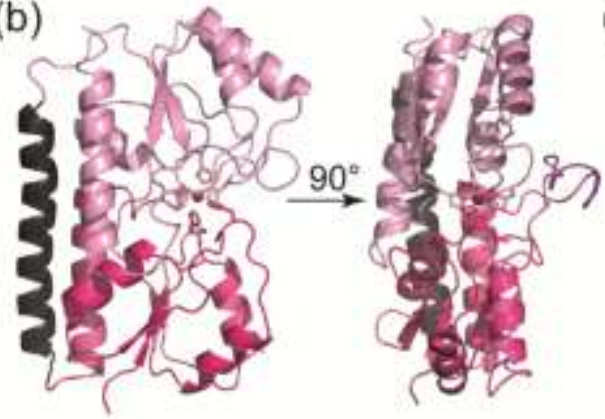

(e)

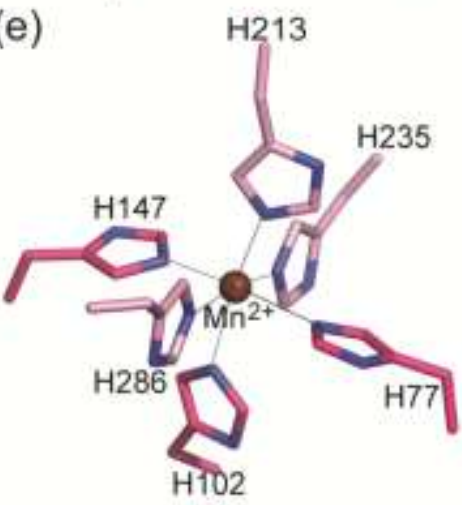

(c)

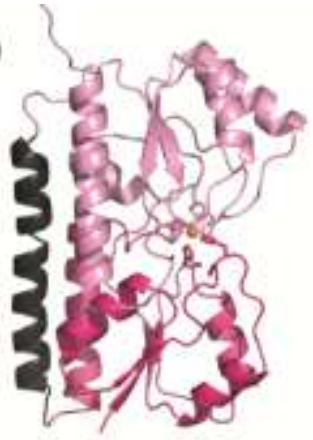

(f)

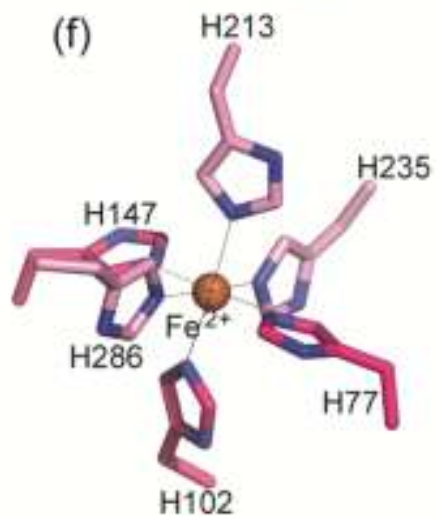

(g)

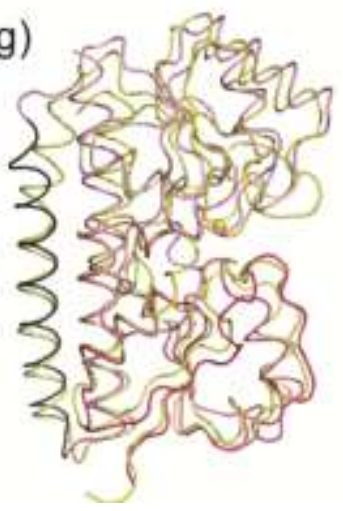

(h)

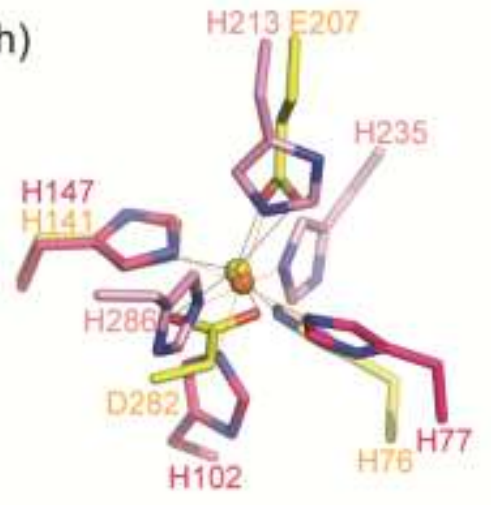

Figure 1. Ribbon representation of His-tag FpvC-metal structure and its metal-binding site. (a) two orthogonal views of His-tag FpvC with the bound $\mathrm{Ni}^{2+}$ in green located in the cleft between the $\mathrm{N}$ terminal and C-terminal domains shown in magenta and pink, respectively, and the helical hinge region is in grey; (b) two orthogonal views of His-tag $\mathrm{FpvC}$ with the bound $\mathrm{Mn}^{2+}$ in brown, , same code colour as (a) for FpvC; (c) one view of His-tag $\mathrm{FpvC}$ with the bound $\mathrm{Fe}^{2+}$ in orange, same code colour as (a) for FpvC. (d, f) Metal coordination showing the hexahistidine (H77, H102, H147, H213, $\mathrm{H} 235$ and H286) site of FpvC: $\mathrm{Ni}^{2+}$ is green (d) $\mathrm{Mn}^{2+}$ is brown (e) $\mathrm{Fe}^{2+}$ is orange (f), metal-histidine interactions are shown as plain black lines. (g) Superposition of His-tag FpvC-Fe ${ }^{2+}$ (some code colour as (a)) and its closest homologue $\mathrm{Yfe} A-\mathrm{Fe}^{2+}$ (yellow; PDB 5UYE) structures. The iron ion is shown in orange in $\mathrm{FpvC}$ while it is in yellow in YfeA. (h) close-up view of the superposed metal binding sites 
of His-tag FpvC-Fe ${ }^{2+}$ (magenta/pink for amino-acids and orange for iron ion) and $\mathrm{YfeA}^{-\mathrm{Fe}^{2+}}$ (yellow). Amino-acids are labelled and metal-protein ligands interactions are shown as plain lines (orange in FpvC and black in YfeA).

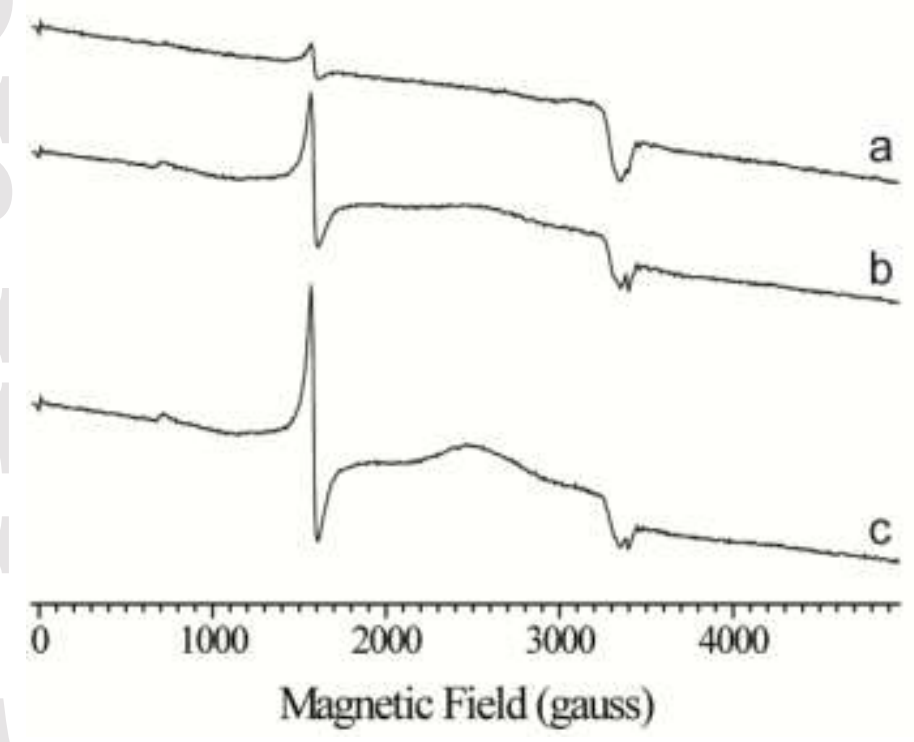

Figure 2. EPR spectra recorded on purified His-tag FpvC-iron complex $(60 \mu \mathrm{M})$ produced from minimal media supplemented with FeSO4: a, spectrum of the protein complex. b, spectrum of the protein complex with $30 \mu \mathrm{M}$ potassium ferricyanide and c, spectrum of the protein complex with 60 $\mu \mathrm{M}$ potassium ferricyanide. Instrument settings: Temperature, $4.2 \mathrm{~K}$; modulation amplitude, $25 \mathrm{G}$; microwave power, $20 \mathrm{~mW}$; microwave frequency, $9.5 \mathrm{GHz}$; modulation frequency, $100 \mathrm{kHz}$.

This article is protected by copyright. All rights reserved. 


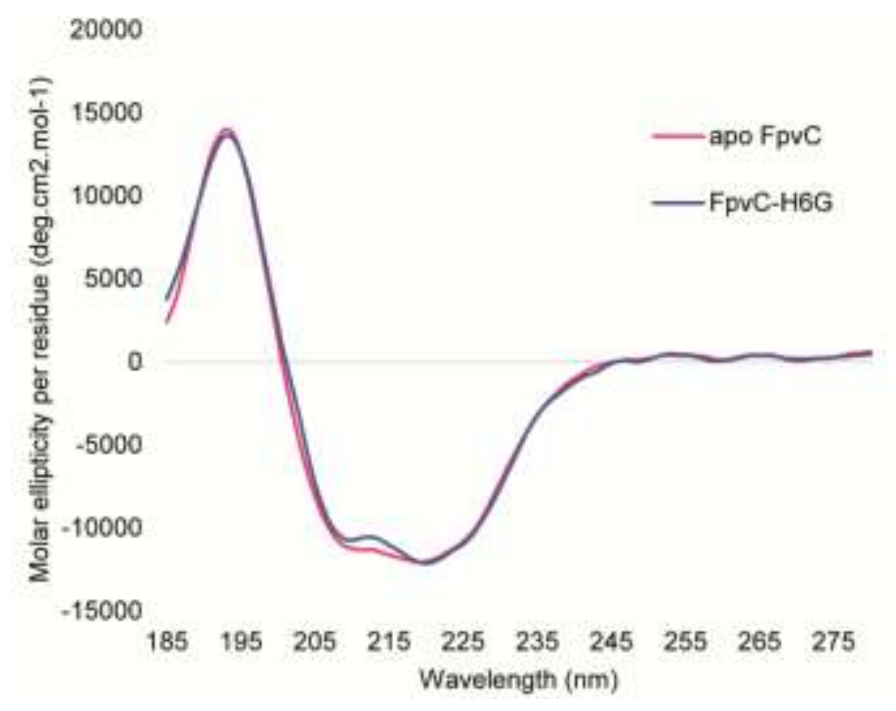

Figure 3. CD analysis spectra of apo FpvC (magenta) and FpvC-H6G mutant (blue).

This article is protected by copyright. All rights reserved. 

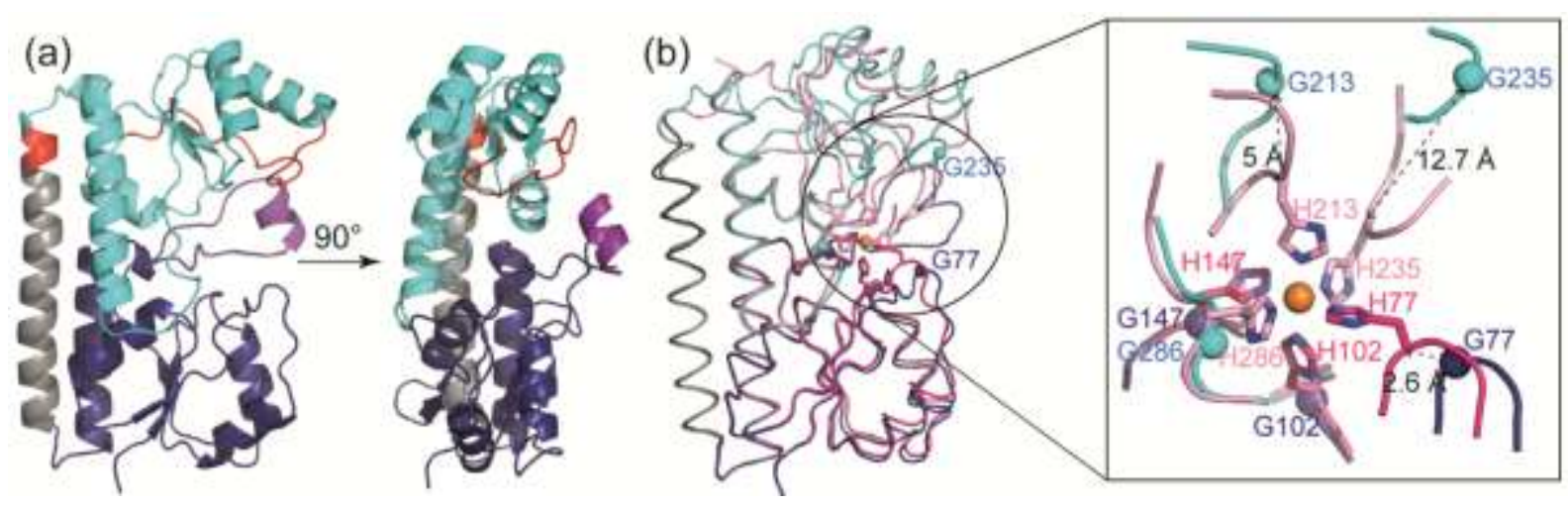

Figure 4. (a) Ribbon representation of metal-free FpvC-H6G mutant structure in two orthogonal views. The N-terminal and C-terminal domains are shown in blue and cyan, respectively, and the helical hinge region is in grey. The C-terminus of the inter-domain helix and the long loop region (residues 224-240) are highlighted in red as they are both subject to large conformation changes upon metal binding. The loop residues 132-141, not visible or poorly defined in the metal-bound FpvC structures is in purple (b) Superposition of His-tag FpvC-Fe ${ }^{2+}$ (magenta and pink, same code colour as Figure 1) and FpvC-H6G mutant (blue and cyan, same code colour as (a)) structures with a close-up view on the metal binding site comparison with the six histidines in labelled stick and the corresponding point glycine mutants in blue spheres. The carbon alpha distances between the moving histidines (H77, H213 and H235) and their glycine mutants are shown in dashed black lines.

This article is protected by copyright. All rights reserved. 
(a)

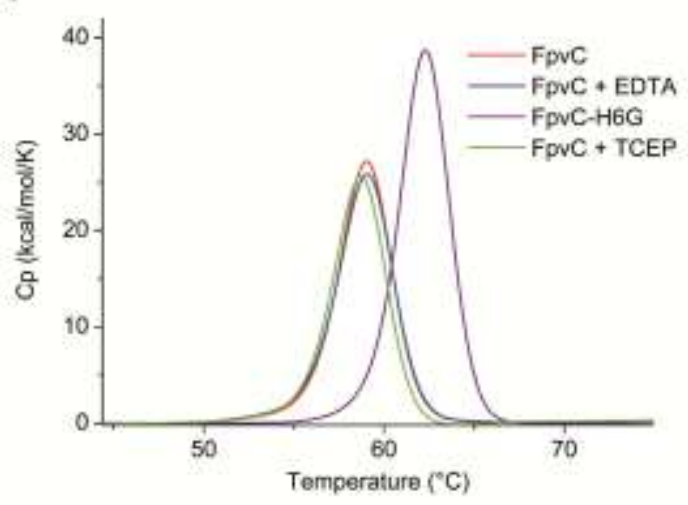

(c) (b)

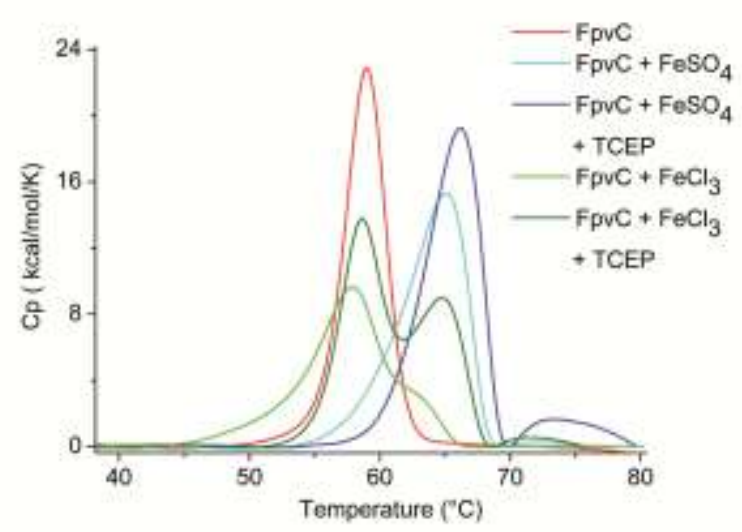

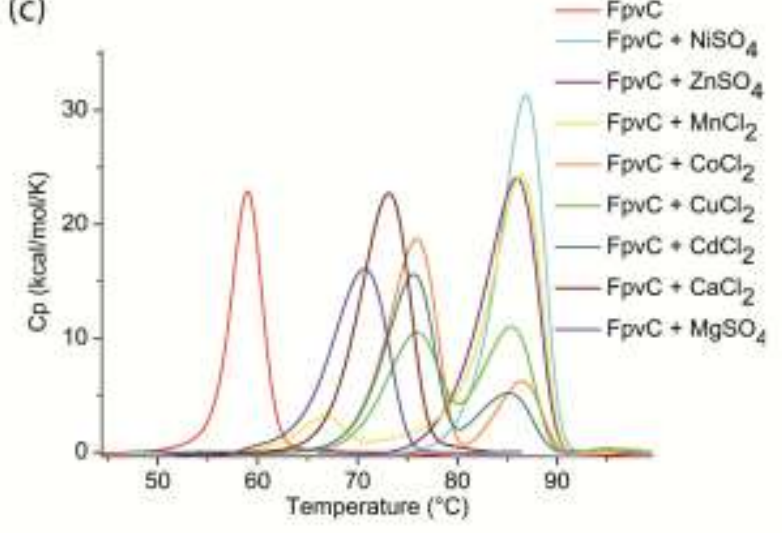

Figure 5. DSC thermograms of apo FpvC devoid of any tag without (a) and with different cations $\left(\mathrm{Fe}^{2+}\right.$ and $\mathrm{Fe}^{3+}$ in (b) and $\mathrm{Ni}^{2+}, \mathrm{Zn}^{2+}, \mathrm{Mn}^{2+}, \mathrm{Co}^{2+}, \mathrm{Cu}^{2+}, \mathrm{Cd}^{2+}, \mathrm{Ca}^{2+}$ and $\mathrm{Mg}^{2+}$ in (c)) and thermogram of FpvC-H6G mutant (a). DSC experiments were performed twice.

This article is protected by copyright. All rights reserved. 

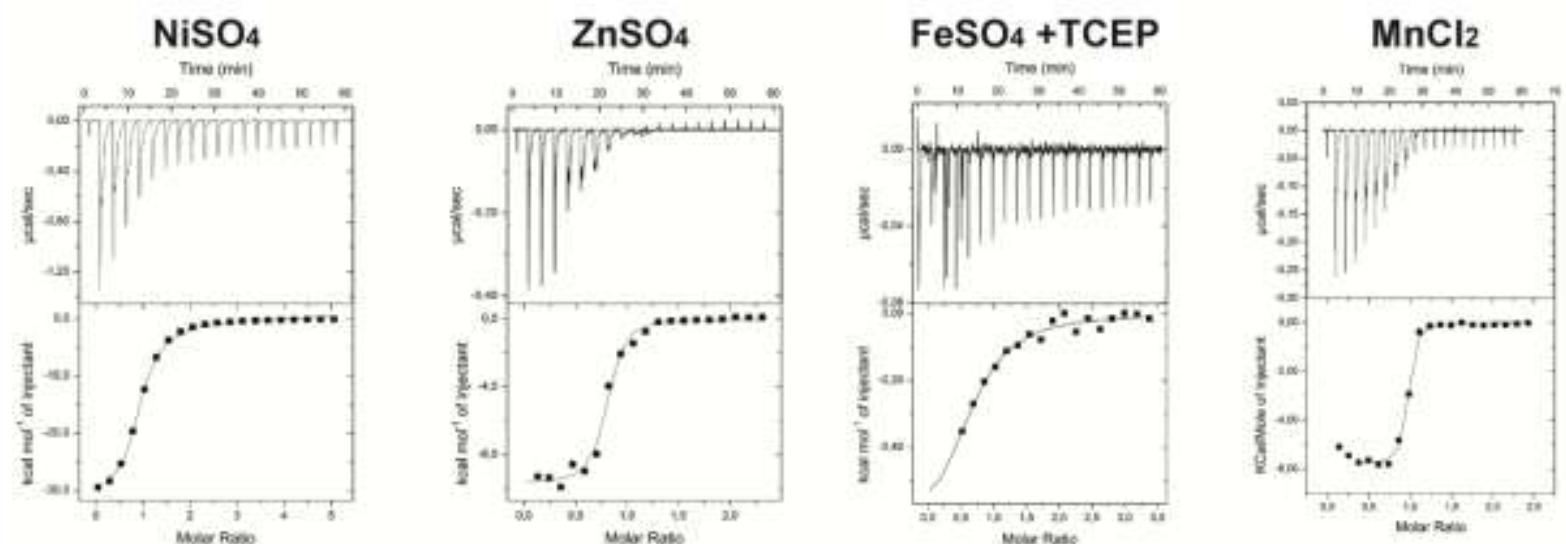

$\mathrm{K}_{\mathrm{D}}=0.19 \pm 0.02 \mu \mathrm{M}$

$K_{D}=0.29 \pm 0.07 \mu \mathrm{M}$

$K_{D}=6.3 \pm 2 \mu M$

$\mathrm{K}_{\mathrm{D}}=0.39 \pm 0.11 \mu \mathrm{M}$

$N=0.87$

$\mathrm{N}=0.76$

$\mathrm{N}=0.7$

$\mathrm{N}=0.92$

$\Delta \mathrm{G}=-23.3 \mathrm{kcal} / \mathrm{mol}$

$\Delta G=-10.6 \mathrm{kcal} / \mathrm{mol}$

$\Delta \mathrm{G}=-7 \mathrm{kcal} / \mathrm{mol}$

$\Delta \mathrm{G}=-7 \mathrm{kcal} / \mathrm{mol}$

$\Delta \mathrm{H}=-16 \mathrm{kcal} / \mathrm{mol}$

$\Delta \mathrm{H}=-9.7 \mathrm{kcal} / \mathrm{mol}$

$\Delta \mathrm{H}=-0.7 \mathrm{kcal} / \mathrm{mol}$

$\Delta \mathrm{H}=-1.2 \mathrm{kcal} / \mathrm{mol}$

$-T \Delta S=-7.3$

$-\mathrm{T} \Delta \mathrm{S}=-0.9$

$-T \Delta S=-6.3$

$-\mathrm{T} \Delta \mathrm{S}=-5.6$

Figure 6. ITC experiments: $K_{\mathrm{D}}$ measurements of apo $\mathrm{FpvC}$ devoid of any tag towards $\mathrm{Ni}^{2+}\left(\mathrm{NiSO}_{4}\right)$, $\mathrm{Zn}^{2+}\left(\mathrm{ZnSO}_{4}\right), \mathrm{Mn}^{2+}\left(\mathrm{MnCl}_{2}\right)$ and $\mathrm{Fe}^{2+}\left(\mathrm{FeSO}_{4}+\mathrm{TCEP}\right)$ ions. The top panel shows heat differences upon injection of metal ion and low panel shows integrated heats of injection with the best fit (solid line) to a single binding model using Microcal ORIGIN. ITC experiments were performed twice.

This article is protected by copyright. All rights reserved. 